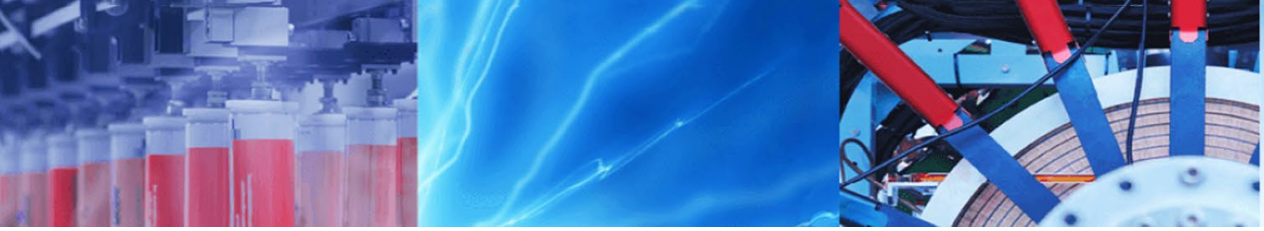

Research Article

\title{
Artificial neural network predication and validation of optimum suspension parameters of a passive suspension system
}

\author{
Mahesh P. Nagarkar ${ }^{1,2} \cdot$ M. A. El-Gohary ${ }^{3} \cdot$ Yogesh J. Bhalerao $^{4} \cdot$ Gahininath J. Vikhe Patil $^{2} \cdot$ Rahul N. Zaware Patil $^{5}$
}

(c) Springer Nature Switzerland AG 2019

\begin{abstract}
This paper presents the modeling and optimization of quarter car suspension system using Macpherson strut. A mathematical model of quarter car is developed, simulated and optimized in Matlab/Simulink environment. The results are validated using test rig. The suspension system parameters are optimized using a genetic algorithm for objective functions viz. vibration dose value (VDV), frequency weighted root mean square acceleration (hereafter called as RMS acceleration), maximum transient vibration value, root mean square suspension space and root mean square tyre deflection. ISO 2631-1 standard is adopted to assess ride and health criterion. Results shows that optimum parameters provide ride comfort and health criterions over classical design. The optimization results are experimentally validated using quarter car test setup. The genetic algorithm optimization results are further extended to the artificial neural network simulation and prediction model. Artificial neural network model is carried out in Matlab/Simulink ${ }^{\circ}$ environment and Neuro Dimensions. Simulation, experimental and predicted results are in close correlation. The optimized system reduces the values of VDV by $45 \%$. Also, RMS acceleration is reduced by $47 \%$. Thus, the optimized system improved ride comfort by reducing RMS acceleration and improved health criterion by reducing the VDV. Finally ANN can be used for predicting the optimum suspension parameters values with good agreement.
\end{abstract}

Keywords Macpherson strut · Genetic algorithm · Multi-objective optimization · Artificial neural network · Quarter car suspension test rig

$\begin{array}{ll}\text { List of symbols } \\ a & \text { Angle made by link OA with horizontal (in }{ }^{\circ} \text { ) } \\ \theta & \text { Rotation angle of control arm (in }{ }^{\circ} \text { ) } \\ \theta o & \text { Initial angular displacement of control arm (in }{ }^{\circ} \text { ) } \\ \mathrm{A}_{\mathrm{ws}} & \begin{array}{l}\text { Frequency weighted RMS Sprung Mass accelera- } \\ \text { tion }\left(\mathrm{m} / \mathrm{s}^{2}\right)\end{array} \\ \mathrm{c} & \text { Damping coefficient (Ns } / \mathrm{m}) \\ \mathrm{f}_{\text {obj }} & \text { Objective function } \\ \mathrm{k} & \text { Stiffness (N/m) } \\ \mathrm{k}_{\mathrm{t}} & \text { Tyre stiffness }(\mathrm{N} / \mathrm{m}) \\ \mathrm{I}_{\mathrm{A}} & \text { Distance from O to } \mathrm{A}(\mathrm{m})\end{array}$

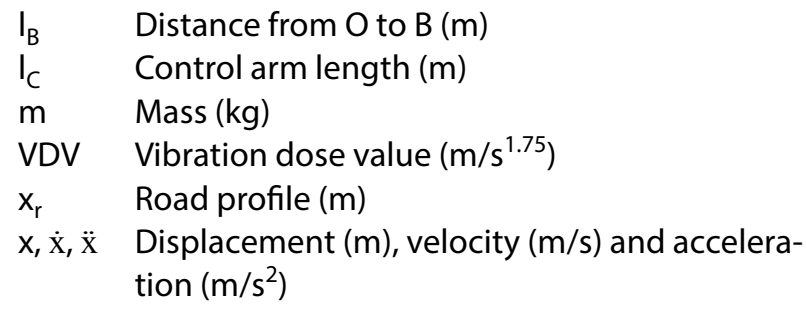

\begin{tabular}{ll}
\multicolumn{2}{l}{ Subscripts } \\
s & Sprung \\
us & Unsprung
\end{tabular}

$\triangle$ Mahesh P. Nagarkar, maheshnagarkar@rediffmail.com | 'SCSM College of Engineering, Ahmednagar, Maharashtra 414005, India. ${ }^{2}$ Research Department of Mechanical Engineering, AVCoE, Sangamner, Maharashtra, India. ${ }^{3}$ Mechanical Engineering Department, Beirut Arab University, Beirut, Lebanon. ${ }^{4}$ MIT Academy of Engineering, Alandi, Pune, Maharashtra 412105, India. ${ }^{5} \mathrm{DVVP}$ CoE, Vilad Ghat, Ahmednagar, Maharashtra 414111, India. 


\section{Introduction}

In an automobile, road-induced vibrations are undesirable as it causes discomfort, fatigue and health issues to the occupants. The main function of the suspension system is to isolate the vehicle body and the occupants from road irregularities, thus providing the ride comfort. Also, suspension system has to support the vehicle weight and to provide handling and to keep tyre and ground contact. Thus suspension system is having conflicting requirements with a trade-off between ride comfort and handling. Due to this, many researchers, to find optimal suspension parameters amongst the conflicting requirements [1], are investigating the suspension system. Verros and Natsivas [2] presented optimization of suspension parameters for a quarter car system traveling on a random road. Authors have showed a comparison of passive linear, semi-active sky-hook and dual rate dampers. Baumal et al. [3] presented optimization of half car suspension system with an aim to provide ride comfort by minimizing passenger seat's accelerations. Genetic algorithm (GA) technique is used to search optimum parameters. Optimization of quarter car and half car model was carried by Ozcan et al. [4], considering root mean square (RMS) acceleration, body roll and tyre forces as objectives. Gobi and Mastinu [5] studied multi-objective optimization of 2 DoF quarter car traversing on the random road. Optimal parameters like spring and tyre stiffness and damping were derived to fulfill ride, suspension working space, and road holding. Molina-Cristobal et al. [6] carried multi-objective optimization of a passive quarter car. Multi-objective GA was implemented to optimize ride comfort and road holding. El-Gohary et al. [7] implemented GA technique to search optimum suspension parameters viz. spring stiffness and damping coefficient for front and rear suspensions of a 7 DoF passive suspension system. The GA technique is used to improve the performance of a passive suspension system at varying velocities. Further Proportional-Integral (PI) controller was implemented to study ride comfort of a 7 DoF suspension model.

Gohari et al. [8] had studied vibrations transmitted to the womb in case of pregnant mothers. An eleven DoF model of pregnant subject with womb was developed and studied for optimization. An ANN was implemented to optimize the bus set suspension so as to minimize the seat to womb vibrations. ANN is designed and optimized using seat mass, stiffness and damping with first two peaks of seat to womb transmissibility. It was observed that optimized seat suspension system minimizes $85 \%$ transmitted vibrations.

In this thesis author [9] had optimized the vehicle suspension system using reinforcement learning technique.
The learning automata introduced active control for full active and semi-active system with an introduction of moderator which prevents excessive deviation. Author had introduced Continuous Action-set Reinforcement Learning Automaton (CARLA) which enables to control in non-stationary environment and gives complete coverage to the action space due to its learning ability. Thus CARLA outperforms the discrete automata. CARLA was also successfully implemented for roll-control.

Artificial neural network (ANN) technique is implemented to predict the optimum parameters. ANN systems are the systems which are developed from the data and knowledge acquired from experience and can be used further for prediction. ANNs learns from experimental data to form a network to predict.

Author [10] had implemented active force control (AFC) technique to actively control the seat suspension of heavy duty vehicles. AFC is integrated with ANN to estimate the mass of driver and seat. An ANN with multi-layer feed forward is trained using Levenberg-Marquardt algorithm. A 2 DoF lumped mass driver model is used along with a quarter car model. AFC technique is simulated and compared with passive suspension system and classical PID controller. Various road profiles are used to check the performance. It was observed that AFC performs better than PID and passive system in minimizing vibrations to driver's seat. M. Gohari and Tahmasebi [11] had described optimization of seat suspension parameters using a Katakazi model of spinal column to reduce transmitted vibrations at spine. An ANN is formulated using seat mass, stiffness, damping and first two peaks of seat to head transmissibility. An ANN was trained and simulated to predict the mass and seat suspension parameters namely stiffness and damping. The results so obtained were in good agreement. Author [12] determined the seat suspension parameters like mass, stiffness and damping using ANN model along with a driver lumped mass model. Author incorporated a 4 DoF Wan-Schimmel biodynamic model in the study. The seat parameters were optimized by ANN, which were found in good agreement.

This article [13] studied a half car model with two-point wheelbase SMC (sliding mode controller). A preview strategy was implemented using semi-active stepper motor drive gas-filled suspension system. Utilizing structural relationship between front and rear wheels, the road information was obtained. Vehicle body acceleration; pitch acceleration; front and rear suspension deflections, front and rear tire deformation, were observed for performance. It was observed that two point semi-active SMC outperformed the single point semi-active SMC, $\mathrm{H}$-inf active and passive suspension system. Zhao et al. [14] had developed an adaptive NN based control for 2 DoF nonlinear quarter car suspension system. A state feedback NN control 
was developed considering parameter uncertainties, road disturbances and actuator saturation. A NN observer was designed for state estimation based on input and output data. The state observer based feedback controller was developed by PSO algorithm. The objective function includes RMS body displacement, tyre deflection, suspension deflection and sprung mass acceleration. The performance of the controller was numerically validated and the results are presented in time domain. Qin et al. [15] had analysed five semi-active suspension control strategies viz. sky hook, hybrid, clipped optimal, model reference SMC and integrated error neuro control. A commercially available inverse continuous damper control was studied on MTS load frame. A quarter car model was implemented for the analysis. Ride comfort characterised by RMS sprung mass acceleration, road holding and rattle space were the performance criterions studied for the control strategies. Simulation result shows that control weight can change the system from ride oriented to road handling oriented. Also, delay time plays an important role where increase in it affects the comfort more than handling.

To solve design optimization problems in mechanical engineering, Dhingra and Rao [16] implemented neural network (NN) by implementing nonlinear neurons. To enhance ride comfort, Kalaivani et al. [17] implemented NN trained PID controller to control active suspension system. To improve ride using NN trained PID controller, RMS sprung mass acceleration was used as a performance index. It was observed that proposed NN controller reduces body displacement, acceleration and rattle space thus improves ride performance. A mathematical model of mid-sized passenger car was developed by ElGohary et al. [18] by implementing inverse dynamics NN

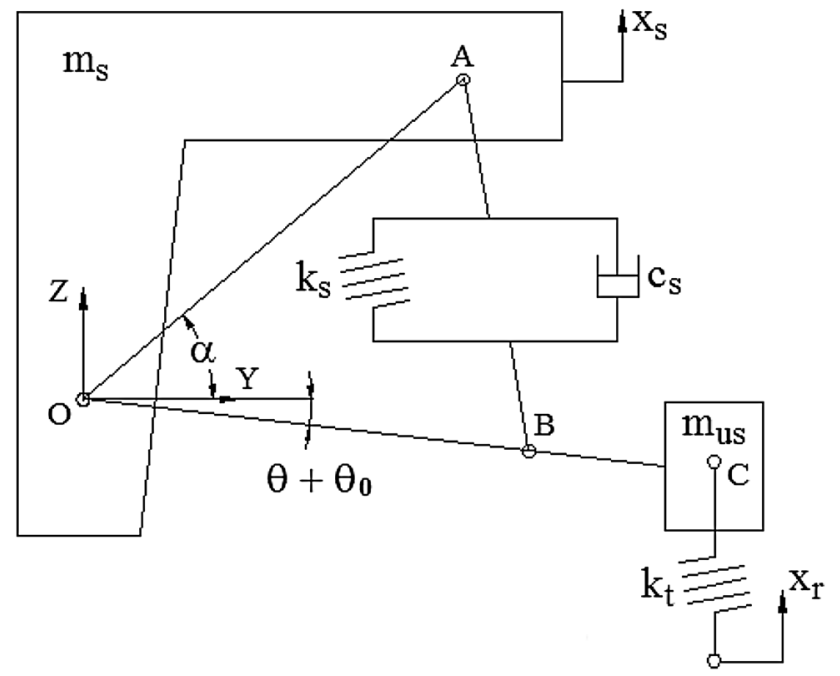

Fig. 1 Quarter car model with Macpherson strut suspension [23] having $1.1 \%$ error between simulated and experimental responses. Optimization of low-speed centrifugal impeller was studied by Marconicini et al. [19] by implementing NN. Authors had selected two types of impellers having 3 blades and 5 blades configuration. The geometry of the blades was parameterized and optimized using NN tool and performance prediction was studied using CFD and correlated by implementing 1D prediction tool. Suction head and efficiency criterions were used to check and compare the performance of both blade configurations. It was observed that $\mathrm{NN}$ results were in good agreement with experimental results. Using manufacturer's data Khalil et al. [20] modelled a artificial neural network (ANN) to predict the trimmed impeller size of a centrifugal pump. Authors had used 90 points to implement and predict ANN. It was observed that the ANN predicted model had less than $0.005 \%$ RMS error as compared to the manufacturer's data. Sahu [21] implemented NN to model and optimize process parameters of material removal rate and tool wear rate by using optimal process parameters. The NN was further optimized using multi-objective optimization using $G A$.

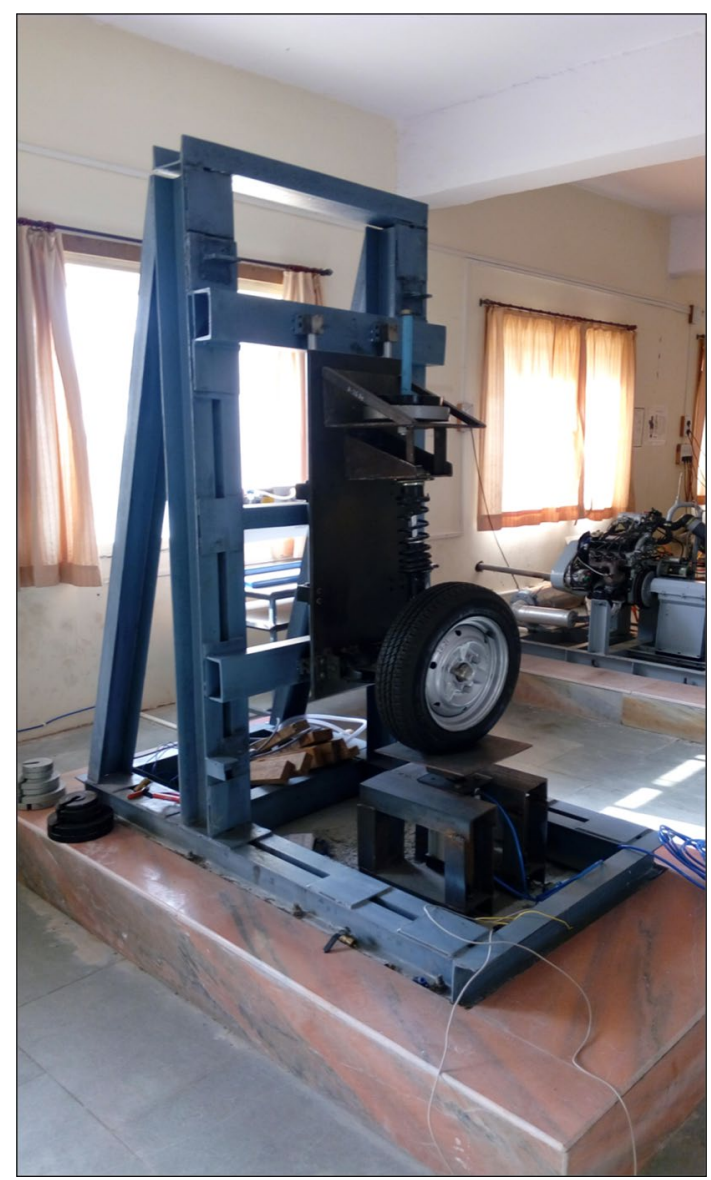

Fig. 2 Quarter car test rig 


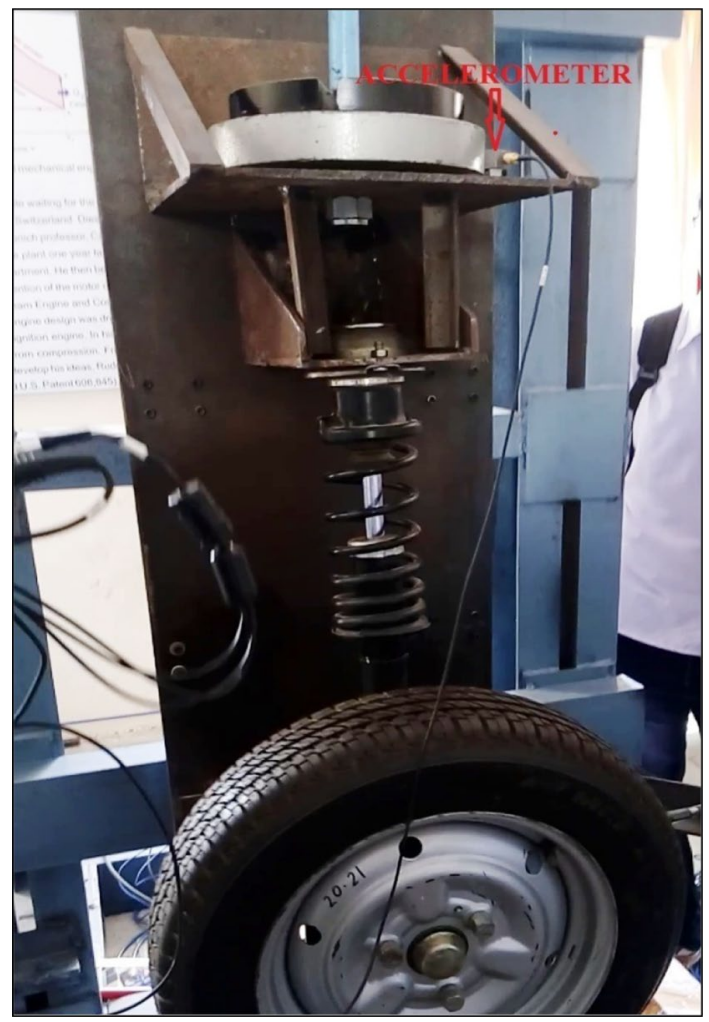

Fig. 3 Position of accelerometers—sprung mass

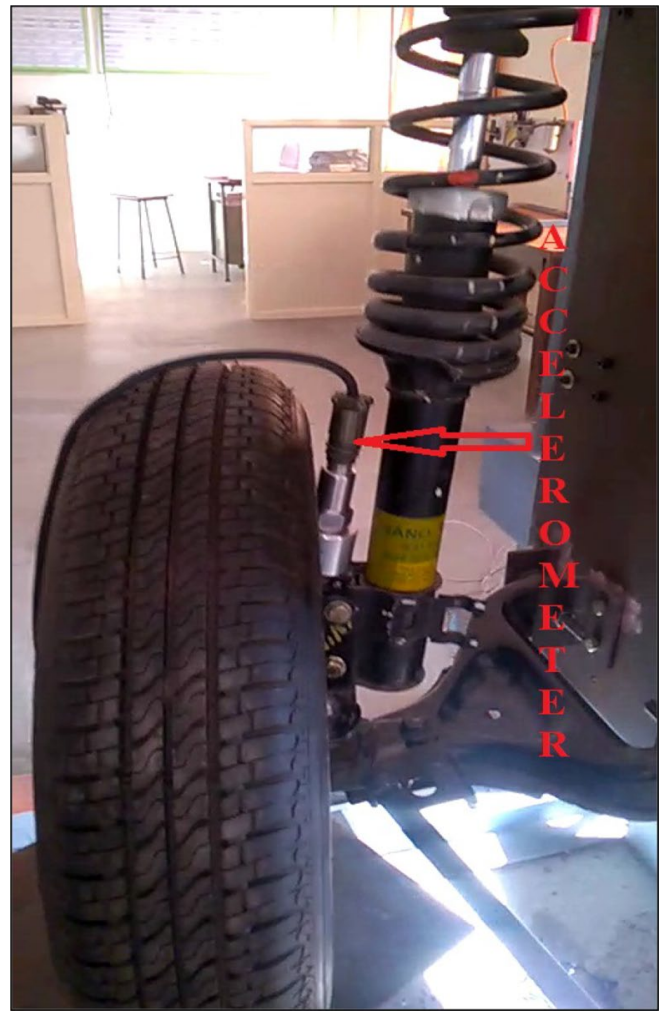

From above literature it is observed that optimization of passive suspension system was carried out by for ride comfort whereas multi-objective optimization was carried out using objectives such as RMS acceleration, road holding and suspension space. Gundogdu [22] carried out multiobjective optimization where multi-objective problem is converted into uni-objective problem using normalization of each objective function and weighting parameters. Whereas Zhao et al. [14] converted a multi-objective fitness function into a uni-objective one using weights. ANNs have applications in the vast fields, from mechanical engineerings in vibration and control, to chemical, pharma drug formulation to centrifugal pumps and in manufacturing processes like EDM. ANNs are successfully implemented to active and/or semi-active control of suspension system. This paper tries to implement ANN to predict the suspension parameters and experimental validation using quarter car test rig. A Macpherson strut quarter-car model is developed and is optimized in Matlab environment using Non-dominated Sort GA (NSGA-II) algorithm. The optimization problem consists of health criterion (including VDV, RMS acceleration, MTVV) and stability criterion (including RMS suspension space and RMS tyre deflection) as an objective functions. For health criterion, ISO 2631-1 is implemented successfully. The optimization data is used to formulate ANN. Matlab and Neuro Dimensions (ND) are used to formulate ANN. ANNs are implemented to predict optimum suspension system parameters for ride comfort and health criterion along with stability criterion. The optimization simulation results, experimental results, and ANN prediction results are represented in the tabular and graphical form.

\section{Methodology}

\subsection{Macpherson strut quarter car model}

To study and optimize the dynamic bahviour a of the Macpherson strut suspension system a mathematical model is developed in Matlab enviroment for ride application. Macpherson strut was developed by Earl Macpherson in 1949 for Ford company. Due to simple design, compactness and light weight it is widely used in vehicles.

Macpherson strut model developed by Hong et al. [23] is implemented in this paper for ride preformance study, multi-objective optimization and ANN prediction. Schematic of Macpherson strutquarter car model is depicted in Fig. 1.

Equation of Motion for Macpherson Strut Model [23] is (Fig. 1):

Fig. 4 Position of accelerometer-unsprung mass 


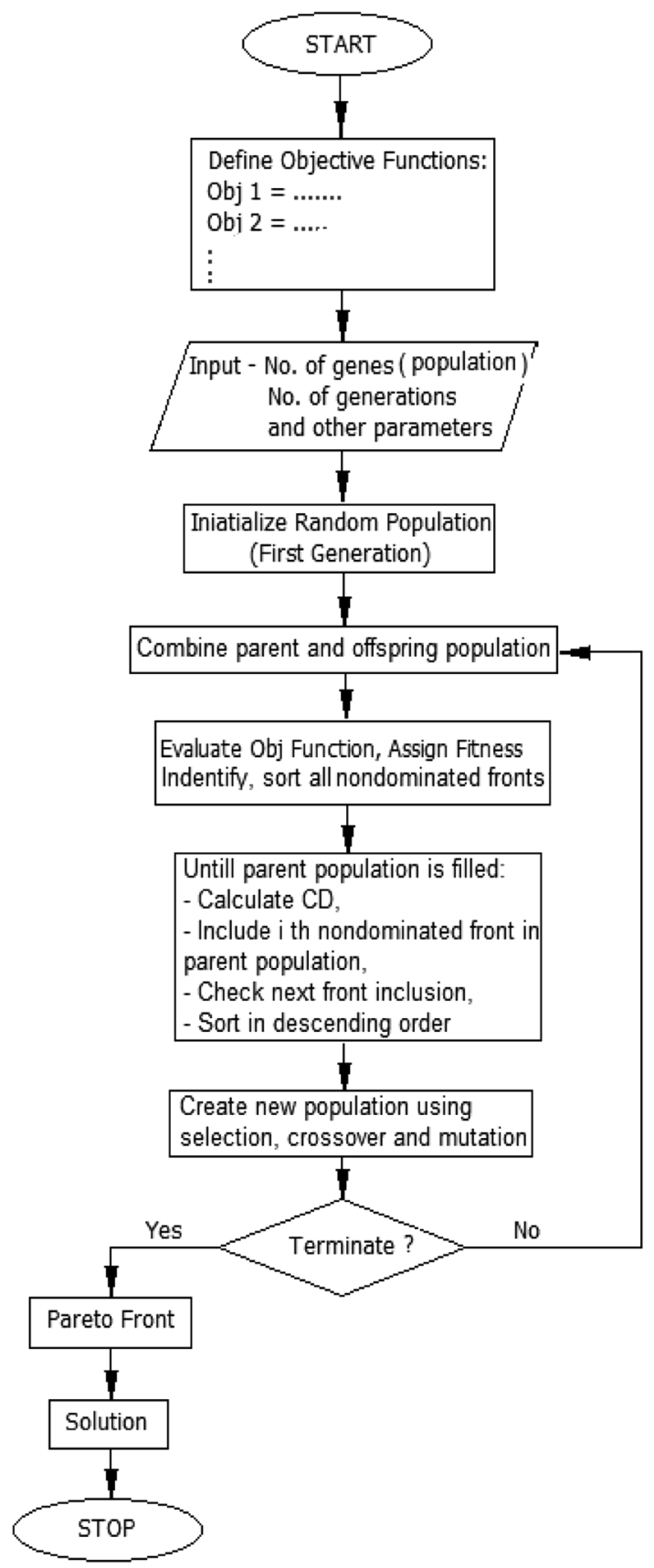

Fig. 5 Flow chart-GA [30]

$$
\begin{aligned}
& \left(\mathrm{m}_{\mathrm{s}}+\mathrm{m}_{\mathrm{us}}\right) \ddot{x}_{\mathrm{s}}+\mathrm{m}_{\mathrm{us}} \mathrm{l}_{\mathrm{c}} \cos \left(\theta-\theta_{0}\right) \ddot{\theta}-\mathrm{m}_{\mathrm{us}} \mathrm{l}_{\mathrm{c}} \sin \left(\theta-\theta_{0}\right) \dot{\theta}^{2} \\
& +\mathrm{k}_{\mathrm{t}}\left(\mathrm{x}_{\mathrm{s}}+\mathrm{l}_{\mathrm{c}}\left(\sin \left(\theta-\theta_{0}\right)-\sin \left(-\theta_{0}\right)-\mathrm{x}_{\mathrm{r}}\right)\right)=0 \\
& \mathrm{~m}_{\mathrm{us}} \mathrm{l}_{\mathrm{c}}^{2} \ddot{\theta}+\mathrm{m}_{\mathrm{us}} \mathrm{l}_{\mathrm{c}} \cos \left(\theta-\theta_{0}\right) \ddot{\mathrm{x}}_{\mathrm{s}}+\frac{\mathrm{c}_{\mathrm{p}} \mathrm{b}_{1}^{2} \sin \left(\alpha^{\prime}-\theta_{0}\right) \dot{\theta}}{4\left(\mathrm{a}_{1}-\mathrm{b}_{1} \cos \left(\alpha^{\prime}-\theta\right)\right)} \\
& +\mathrm{k}_{\mathrm{t}} \mathrm{l}_{\mathrm{c}} \cos \left(\theta-\theta_{0}\right)\left(\mathrm{x}_{\mathrm{s}}+\mathrm{l}_{\mathrm{c}} \sin \left(\theta-\theta_{0}\right)-\sin \left(-\theta_{0}\right)\right) \\
& -\mathrm{x}_{\mathrm{r}}-\frac{1}{2} \mathrm{k}_{\mathrm{s}} \sin \left(\alpha^{\prime}-\theta\right)\left[\mathrm{b}_{1}+\frac{\mathrm{d}_{1}}{\left(\mathrm{c}_{1}-\mathrm{d}_{1} \cos \left(\alpha^{\prime}-\theta\right)^{\frac{1}{2}}\right)}\right]=0
\end{aligned}
$$

where, $\alpha^{\prime}=\alpha+\theta_{0}, \quad \mathrm{a}_{1}=\mathrm{l}_{\mathrm{A}}^{2}+\mathrm{l}_{\mathrm{B}}^{2}, \quad \mathrm{~b}_{1}=2 \mathrm{I}_{\mathrm{A}} \mathrm{l}_{\mathrm{B}}$, $c_{1}=a_{1}^{2}-a_{1} b_{1} \cos \left(\alpha-\theta_{0}\right), d_{1}=a_{1} b_{1}-b_{1}^{2} \cos \left(\alpha-\theta_{0}\right)$

Here,

$\mathrm{m}_{\mathrm{s}}=72.21, \mathrm{~m}_{\mathrm{us}}=23.56, \mathrm{k}_{\mathrm{t}}=101,134, \mathrm{I}_{\mathrm{A}}=0.70, \mathrm{I}_{\mathrm{B}}=0.35$, $\mathrm{I}_{C}=0.40, \theta 0=-5 \mathrm{a}=60$.

\subsection{Quarter car test setup}

A test rig representing quarter car with Macpherson strut is developed and available at Department of Mechanical Engineering, SCSMCoE, Ahmednagar. The test rig is having sprung mass $\left(m_{s}\right)$ represented by a plate and unsprung mass $\left(\mathrm{m}_{\mathrm{us}}\right.$ ) consisting of strut, tie rod, tyre with rim and lower control arm etc. Two vertical guide shafts are attached to the fixed support frame and four linear bearings are mounted on the sprung mass plate to achieve the vertical motion of the frame. The quarter car test setup is shown in Fig. 2. SVAN 958A, a Class 1 four channel sound and vibration analyzer, is used to record the acceleration of sprung mass and unsprung mass. Mounting of the accelerometers is shown in Figs. 3 and 4.

\subsection{Multi-objective optimization}

Gohari and Tahmasebi [24] had presented optimization of seat suspension of off-road vehicle using three algorithm namely genetic algorithm, particle swam optimization and harmony search algorithm. An ANN bionic model based on experimental data is used in this study. The aim was to minimize the vibrations transmitted to the driver's spine thus to reduce the lower back pain. The results thus obtained through three algorithms were checked by simulating Kitazaki model.

The optimization problem is formulated using objective such as-VDV, RMS sprung mass acceleration, MTVV, suspension space deflection and dynamic tyre force. Thus the optimization problem becomes a multi-objective optimization with conflicting objectives.

GA, invented by Holland [25], meta-heuristic algorithm uses the principle of genetics and natural selection to search optimum solution. GA is based on stochastic operators such as reproduction, cross-over and mutation. In this study, for multi-objective optimization, a non-dominated sort genetic algorithm-II (NSGA-II) is implemented [26-28].

NSGA-II compares each individual solution with the remaining solutions in the population to sort the dominance. It then identifies all non-dominated solutions and non-dominated fronts and are ranked. Fitness value 1 is assigned to rank 1 individuals, for rank 2 fitness 2 is assigned and so on. NSGA-II has introduced a new operator called as crowding distance (CD) which represents diversity on individuals in the non-dominated population. 
Table 1 Design variables range

\begin{tabular}{llll}
\hline Design variable & Range & Size & \\
\hline $\mathrm{k}_{\mathrm{s}}(\mathrm{N} / \mathrm{m})$ & $23,027-7675=15,352$ & $2^{13}=8192<13,000<2^{14}=16,384$ & 14 bits \\
$\mathrm{c}_{\mathrm{s}}(\mathrm{N} \mathrm{s} / \mathrm{m})$ & $692-230=462$ & $2^{8}=256<140<2^{9}=512$ & 09 bits \\
\hline
\end{tabular}

Fig. 6 ANN structure

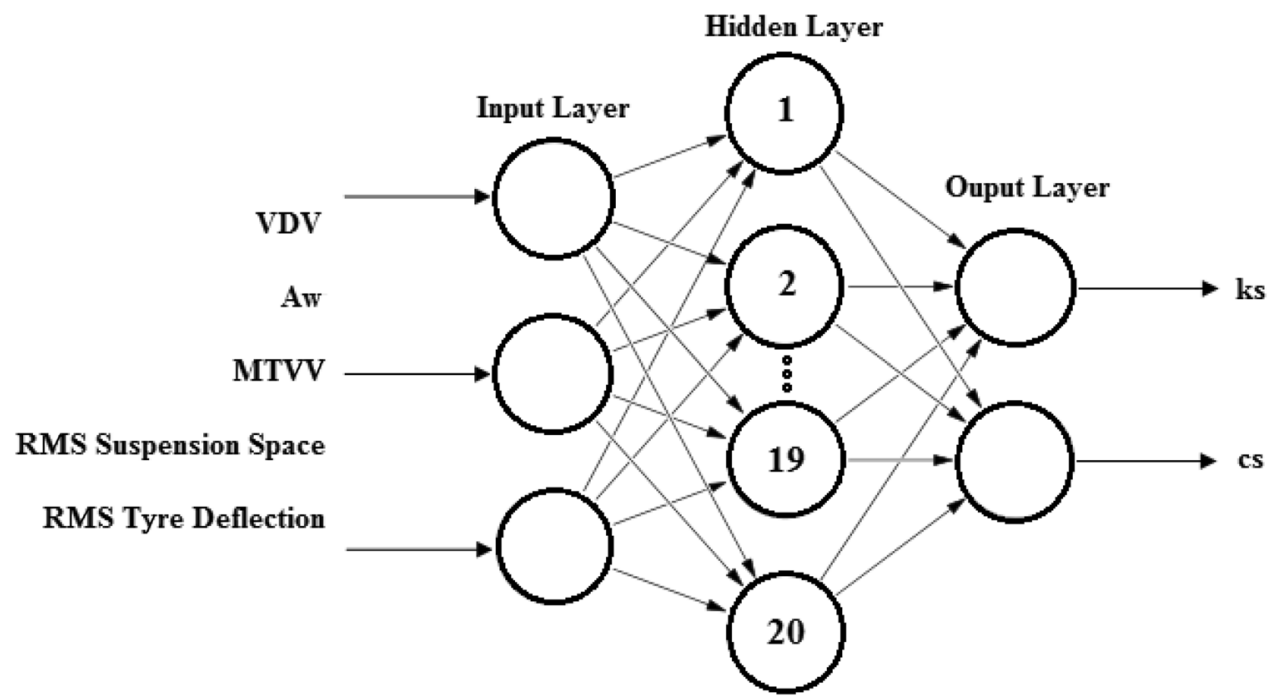

Thus more $C D$ value indicates more diversity. $C D$ is assigned to each individual, front-wise. The individuals on the boundary have infinite $C D$, hence they are always selected. Tournament selection method is used to select parents by comparing CD. Crossover and mutation operators are used to create new off-springs. New off-springs and the parents i.e. current population are combined to generate new population. Selection is carried out for next generation individuals. NSGA-II uses binary tournament method to handle constraints and to decide feasible solutions. Figure 5 shows a flowchart for GA to implement multi-objective optimization.

\subsubsection{Objective functions}

The solution of optimization problem involves proper choice of objective functions. In this study, the suspension system is aimed at optimizing ride comfort and health by considering responses such as RMS acceleration, VDV and MTVV $[24,29]$. Along with these objective functions, suspension space deflection and dynamic tyre force are included as objective functions. Thus it forms a multiobjective optimization problem [30].

RMS Acceleration: The frequency weighted RMS acceleration is obtained as defined by ISO 2631-1 [31]. It is given by
Table 2 ANN parameters-matlab implementation

\begin{tabular}{ll}
\hline Parameter & Description \\
\hline Training & Leverberg-Marquardt (trainlm) \\
Performance & Mean square error (MSE) \\
Transfer function & Tansig \\
Network & Feed forward back propagation \\
Learning function & Learngdm \\
Hidden layer & 01 \\
No of neurons & 25 \\
Maximum Epoch & 1000 \\
\hline
\end{tabular}

$A_{w s}=\left\{\frac{1}{T} \int_{0}^{T}\left[a_{w}(t)\right]^{2} d t\right\}^{\frac{1}{2}}$

Whole-body vibrations (WBV) which are characterized by vertical vibrations transmitted along the vertebral axis through the buttocks and back of the occupant via the base [29]. The WBV mostly affects the human body. With increase in exposure time to vibrations, the health risk also increases. VDV is one of the measures to assess WBV. VDV is the dose of vibrations thus assesses the cumulative effect. VDV is the fourth power of the vibration dose. 
Fig. 7 ANN topology-matlab implementation

Fig. 8 MSE variation with respect to epoch - matlab
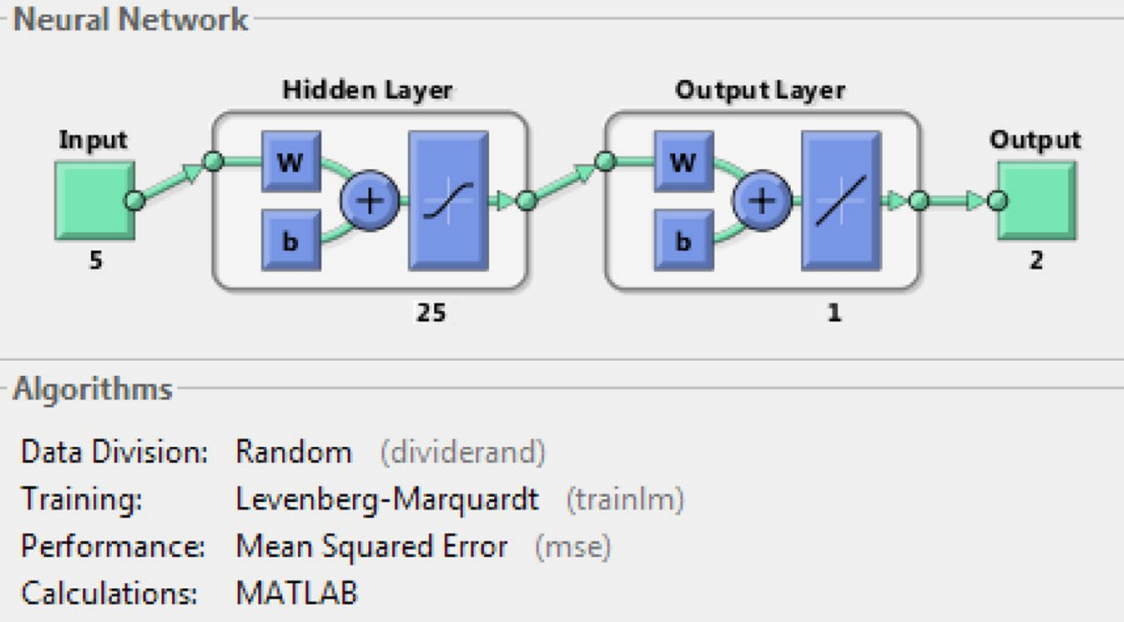

- Progress

Epoch:

Time:

Performance:

0

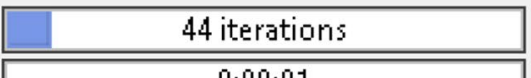

500

Gradient:

0:00:01

Mu:

$2.32 \mathrm{e}+07$

$3.78 \mathrm{e}+07$

0.00100

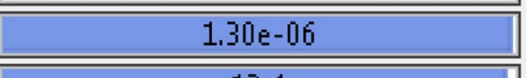

$1.00 \mathrm{e}-07$

Validation Checks:

0

$1.00 \mathrm{e}-07$

$1.00 \mathrm{e}+10$

6

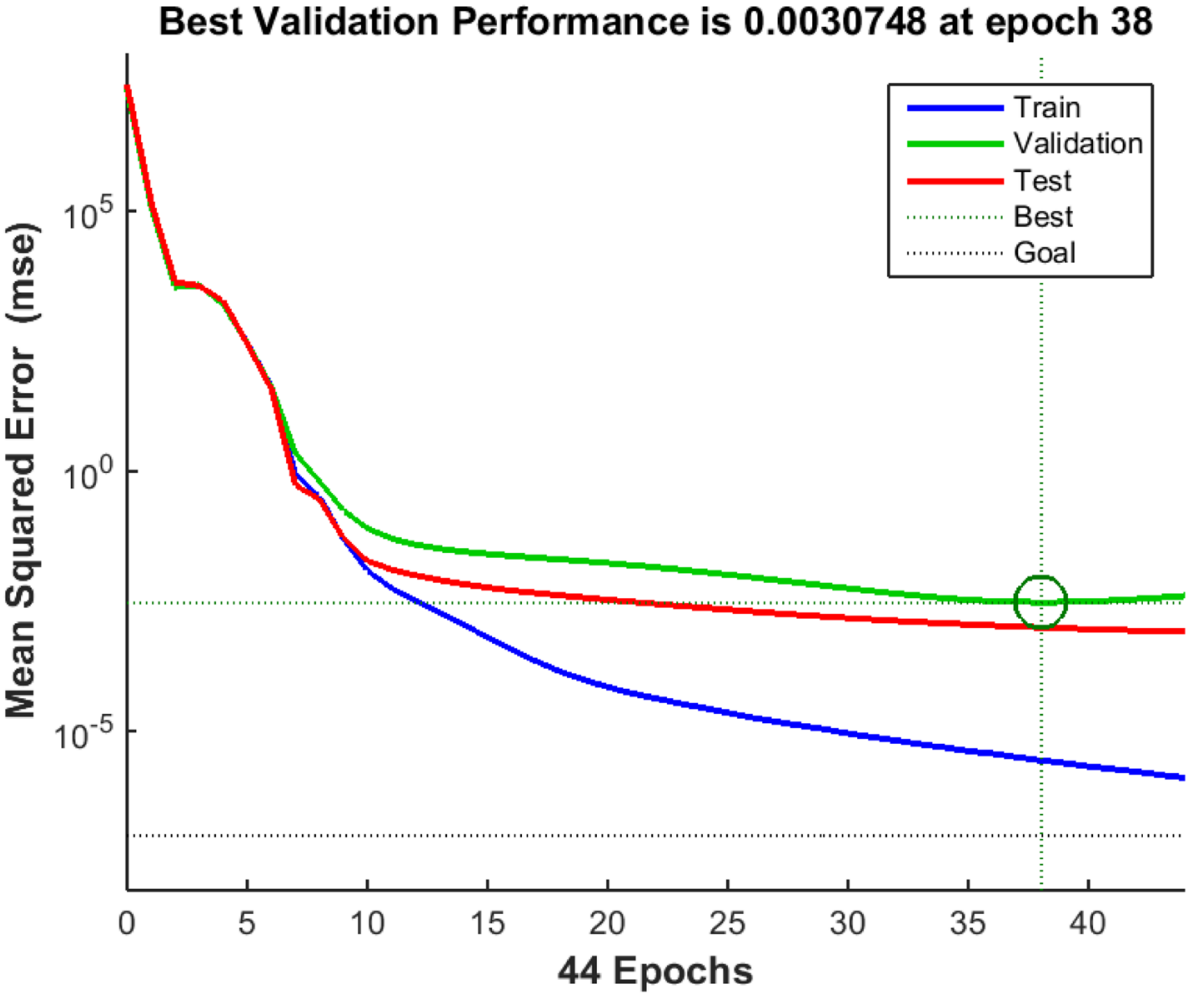



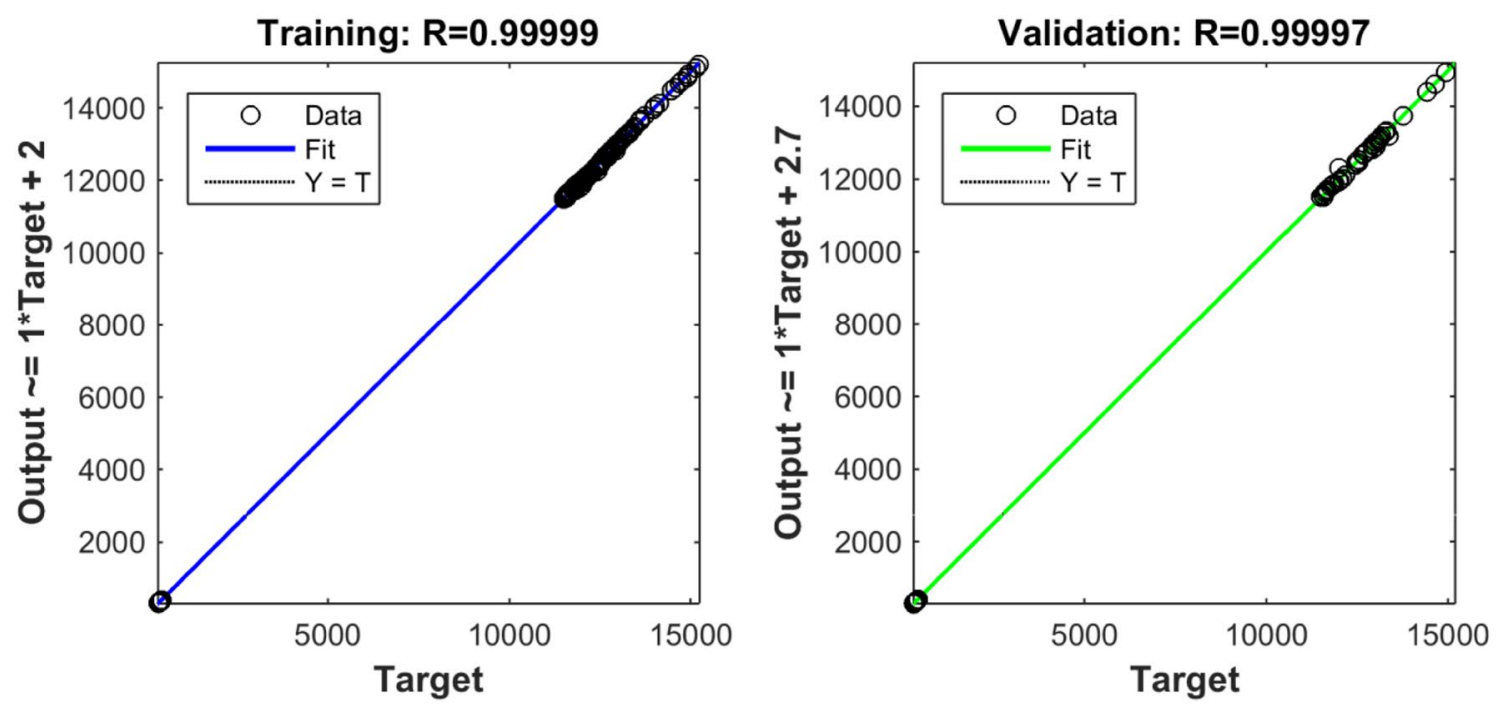

Test: $\mathbf{R}=0.99998$

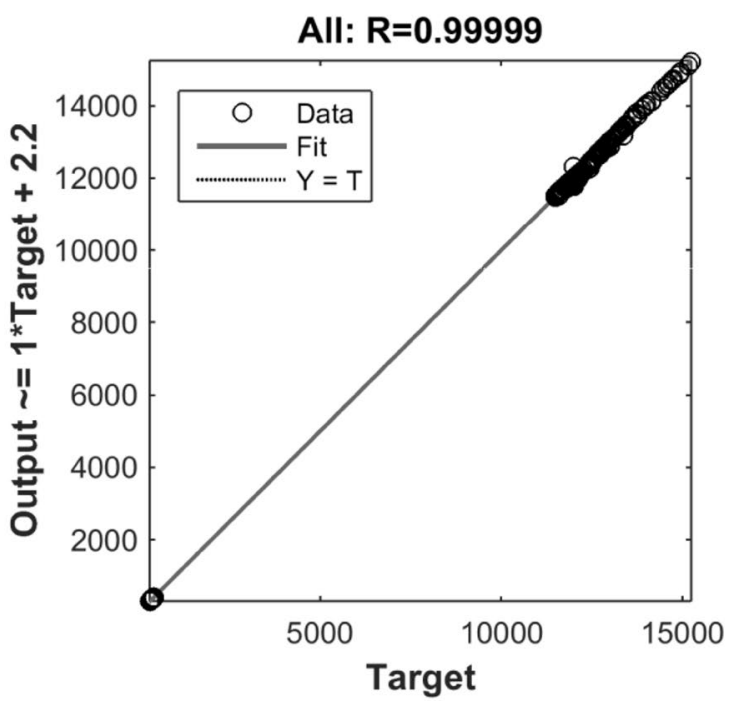

Fig. 9 Correlation coefficients-ANN by nftool

Table 3 ANN parameters-ND implementation

\begin{tabular}{ll}
\hline Parameter & Description \\
\hline Expert wizard & Generalized \\
Data & $\begin{array}{c}\text { 75\% training, 15\% test- } \\
\text { ing and 10\% validation }\end{array}$ \\
Hidden layer & 01 \\
Transfer function & TanhAxon \\
Training & Laverberg-Marquardt \\
Maximum epoch & 1000 \\
Termination & Mean square error (MSE) \\
\hline
\end{tabular}

Vibration Dose Value (VDV): VDV is the measure of vibration dose and is characterized by the fourth power of acceleration [31]. VDV is defined as -

$\operatorname{VDV}_{\mathrm{s}}=\left\{\int_{0}^{\mathrm{T}}\left[\mathrm{a}_{\mathrm{w}}(\mathrm{t})\right]^{4} \mathrm{dt}\right\}^{\frac{1}{4}}$

Maximum Transient Vibration Value (MTVV): It is the highest maximum vibration level during a measurement period [22].

$M T V V=\max \left(a_{w}\right)$ 


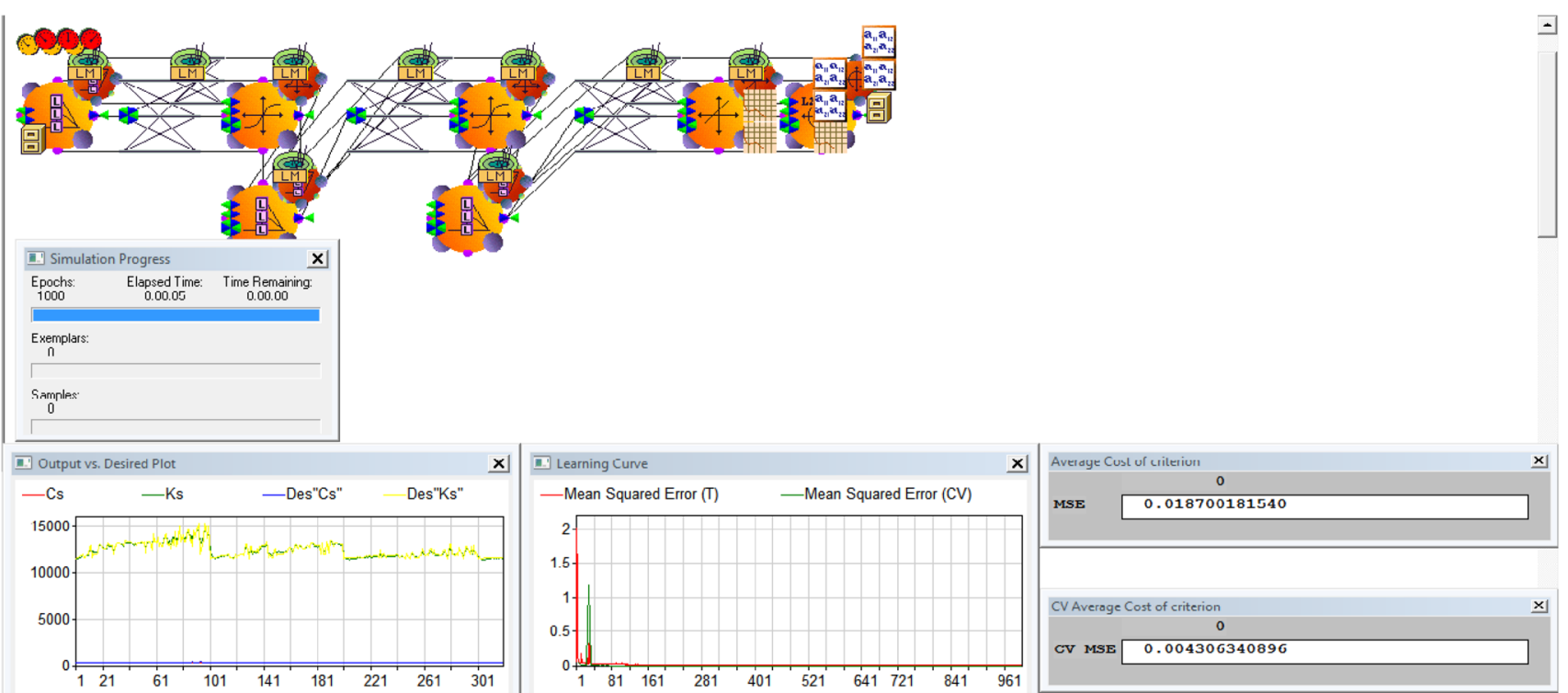

Fig. 10 ANN topology-ND implementation

Suspension Travel: Suspension travel is relative displacement between the sprung mass and unsprung mass. It is expressed as -

$$
\text { Suspension Travel }=\mathrm{x}_{\mathrm{s}}-\mathrm{x}_{\mathrm{us}}
$$

In this paper RMS suspension travel is introduced as one of the objective functions [3,22].

RMS Suspension Travel $=\left\{\frac{1}{T} \int_{0}^{T}\left[\left(x_{s}(t)-x_{u s}(t)\right)\right]^{2} d t\right\}^{\frac{1}{2}}$

Dynamic Tyre deflection: The tyre deflection is the measure of dynamic tyre force. The tyre deflection is expressed as -

Tyre Deflection $=\mathrm{x}_{\mathrm{us}}-\mathrm{x}_{\mathrm{r}}$

RMS of tyre deflection is next objective function.

RMS Tyre Deflection $=\left\{\frac{1}{T} \int_{0}^{T}\left[\left(x_{u s}(t)-x_{r}(t)\right)\right]^{2} d t\right\}^{\frac{1}{2}}$

According to Baumal et al. [3], at least, $125 \mathrm{~mm}$ of suspension travel is required and maximum seat acceleration should not increase $4.5 \mathrm{~m} / \mathrm{s}^{2}$ to avoid hitting the suspension stops. For minimum dynamic tyre forces, the maximum tyre deflection should not exceed $0.058 \mathrm{~m}$. These parameters are included as constraints in the optimization problem.
The formulation of optimization problem is as follows -

$\mathrm{f}_{\text {obj1 }}=$ Minimize (VDV)

$f_{\text {obj2 }}=$ Minimize $\left(A_{w}\right)$

$\mathrm{f}_{\mathrm{obj} 3}=$ Minimize (MTVV)

$\mathrm{f}_{\text {obj4 }}=$ Minimize (RMS suspension travel)

$\mathrm{f}_{\mathrm{obj} 5}=$ Minimize (RMS tyre deflection)

Subject to constraints:

$\mathrm{a}_{\text {max_seat }} \leq 4.5 \mathrm{~m} / \mathrm{s}^{2}, \max .\left(\mathrm{x}_{\mathrm{s}}-\mathrm{x}_{\mathrm{us}}\right) \leq 0.125 \mathrm{~m}$,

$\operatorname{Max} .\left(\mathrm{x}_{\mathrm{us}}-\mathrm{x}_{\mathrm{r}}\right) \leq 0.058 \mathrm{~m}$

Search Space:

During optimization, the design parameters are suspension spring stiffness and suspension damping. The search space is give as:

$k_{s} \in \pm 50 \% k_{s}, \quad c_{s} \in \pm 50 \% c_{s},[22,30]$. Hence, $k_{s} \in[7675,23027], c_{s} \in[230,692]$

\subsubsection{Population-GA}

The population for GA algorithm is calculated based on the range of design variables. The range of $k_{s}$ is $(230,227-7675=) 15,352$. This indicates that $k_{s}$ need to be divided into 15,352 equal range of size. Hence $2^{13}=8192<13,000<2^{14}=16,384$ i.e. 14 bits are required to store value of design variable $k_{s}$ in the chromosome. 
Fig. 11 Test rig results-time domain - simulation and experimental
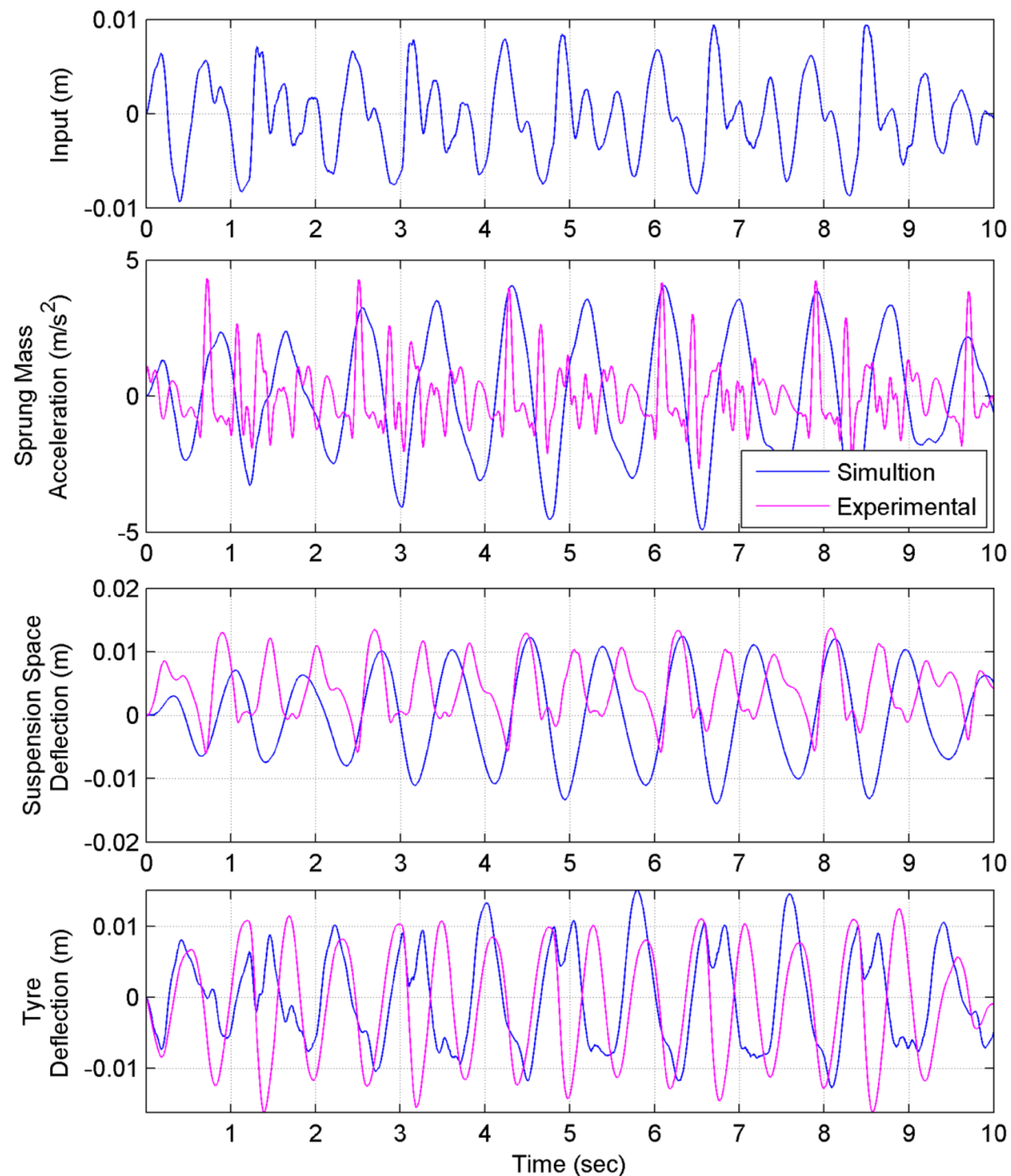

Table 4 Test rig results_-simulate and experimental

\begin{tabular}{lll}
\hline Parameter & Simulated & Experimental \\
\hline VDV & 2.5543 & 2.8648 \\
AW & 1.1707 & 1.0757 \\
MTVV & 2.1649 & 3.9336 \\
RMS Suspension Space & 0.0071 & 0.0062 \\
RMS Tyre Deflection & 0.0068 & 0.0081 \\
Max Acceleration & 4.9087 & 4.3136 \\
Max Suspension Space & 0.0139 & 0.0137 \\
Max Tyre Deflection & 0.0152 & 0.0163 \\
\hline
\end{tabular}

Similarly, for other design variable, $c_{s}$ the bit required is tabulated in Table 1.

Hence the total length of chromosome or gene is $(14+09=) 23$ bits, where first 14 bits are needed for $k_{s^{\prime}}$ and next 09 bits are for $c_{s}$. Population size is then selected such that:

$\mathrm{N}_{\mathrm{s}}<$ population size $<2 \mathrm{~N}_{s^{\prime}}$ where $\mathrm{N}_{\mathrm{s}}=$ string length [32].

Thus, selecting population size of $100[30,33,34]$ and algorithm is stopped after 100 generations. 
Fig. 12 Frequency response plot for simulated and experimental results-un-optimized strut

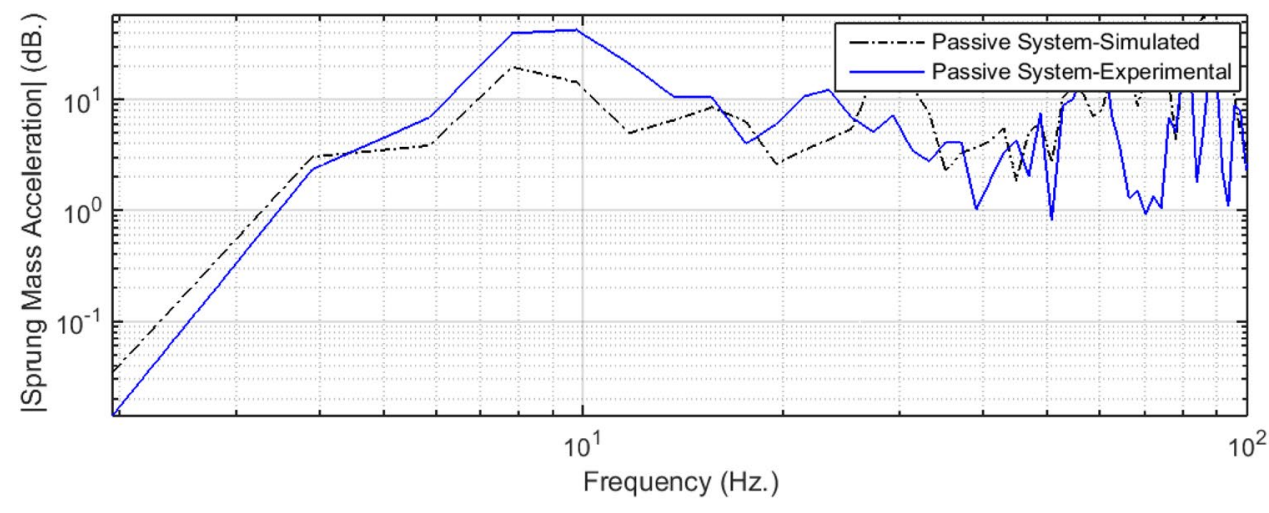

Fig. 13 Trade-off front-NSGAIl optimization

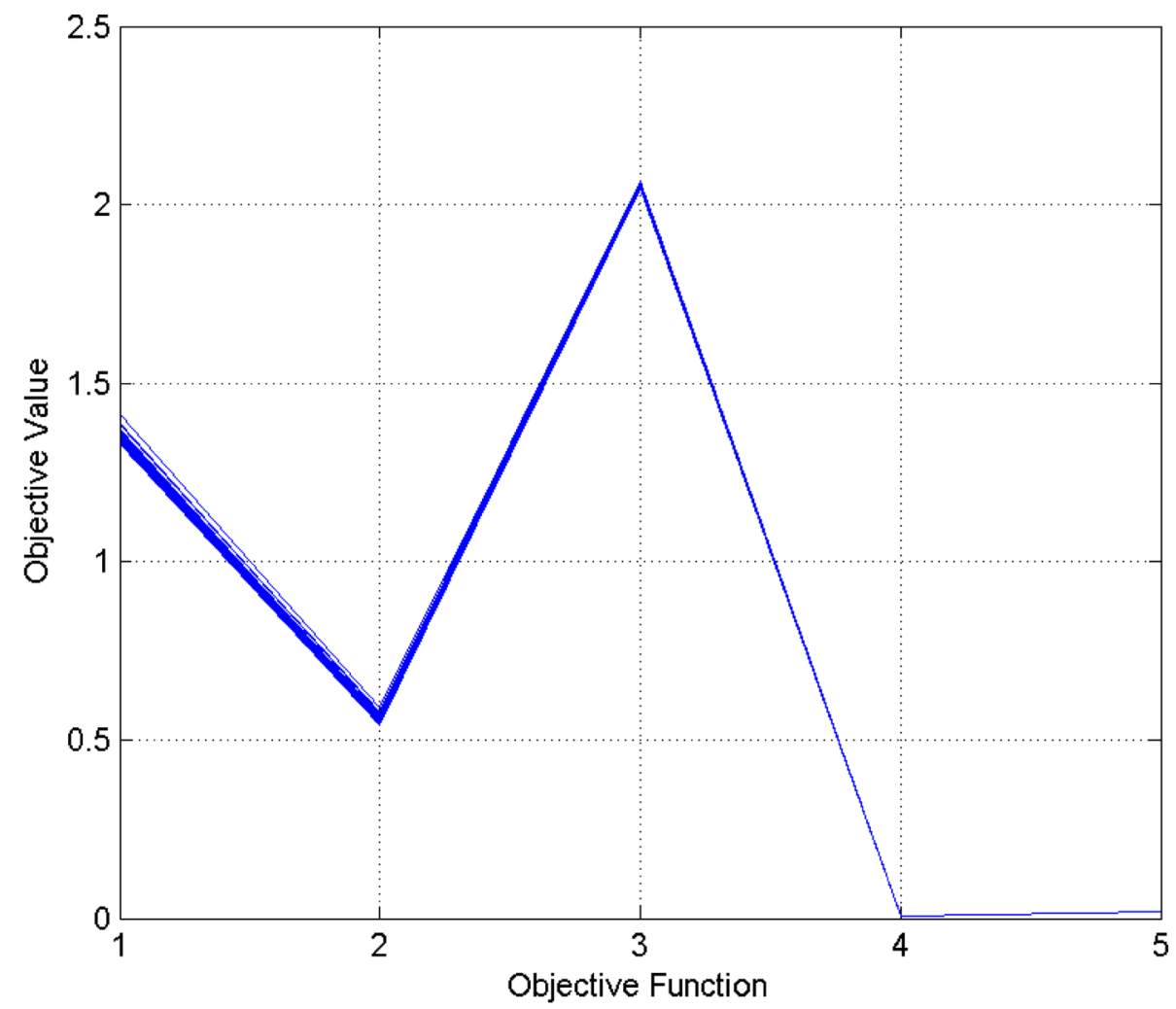

Table 5 Suspension parameter-un-optimized, optimized, predicted

\begin{tabular}{|c|c|c|c|c|}
\hline \multirow[t]{2}{*}{ Parameter } & \multirow{2}{*}{$\begin{array}{l}\text { Un-opti- } \\
\text { mized }\end{array}$} & \multirow{2}{*}{$\begin{array}{l}\text { Optimized } \\
\text { - GA }\end{array}$} & \multicolumn{2}{|l|}{ Predicted } \\
\hline & & & $\begin{array}{l}\text { Nftool- } \\
\text { Matlab }\end{array}$ & ANN-ND \\
\hline $\mathrm{Ks}(\mathrm{N} / \mathrm{m})$ & $15,351.08$ & $11,509.5131$ & $11,500.6428$ & $11,504.1174$ \\
\hline Cs (N s/m) & 461.30 & 318.3712 & 320.1467 & 325.9211 \\
\hline
\end{tabular}

\section{Artificial neural networks (ANN)}

ANN is a reliable and robust predicting tool which is based on the data, variables and the training domain. ANN is a feed-forward network in which unidirectional information propagation takes place. This ensures steady state network. Figure 6 represents general structure of ANN. ANN creates a network, trains it and simulates and validates a 
Fig. 14 Test rig experimental results - time domain -optimized and un-optimized parameters
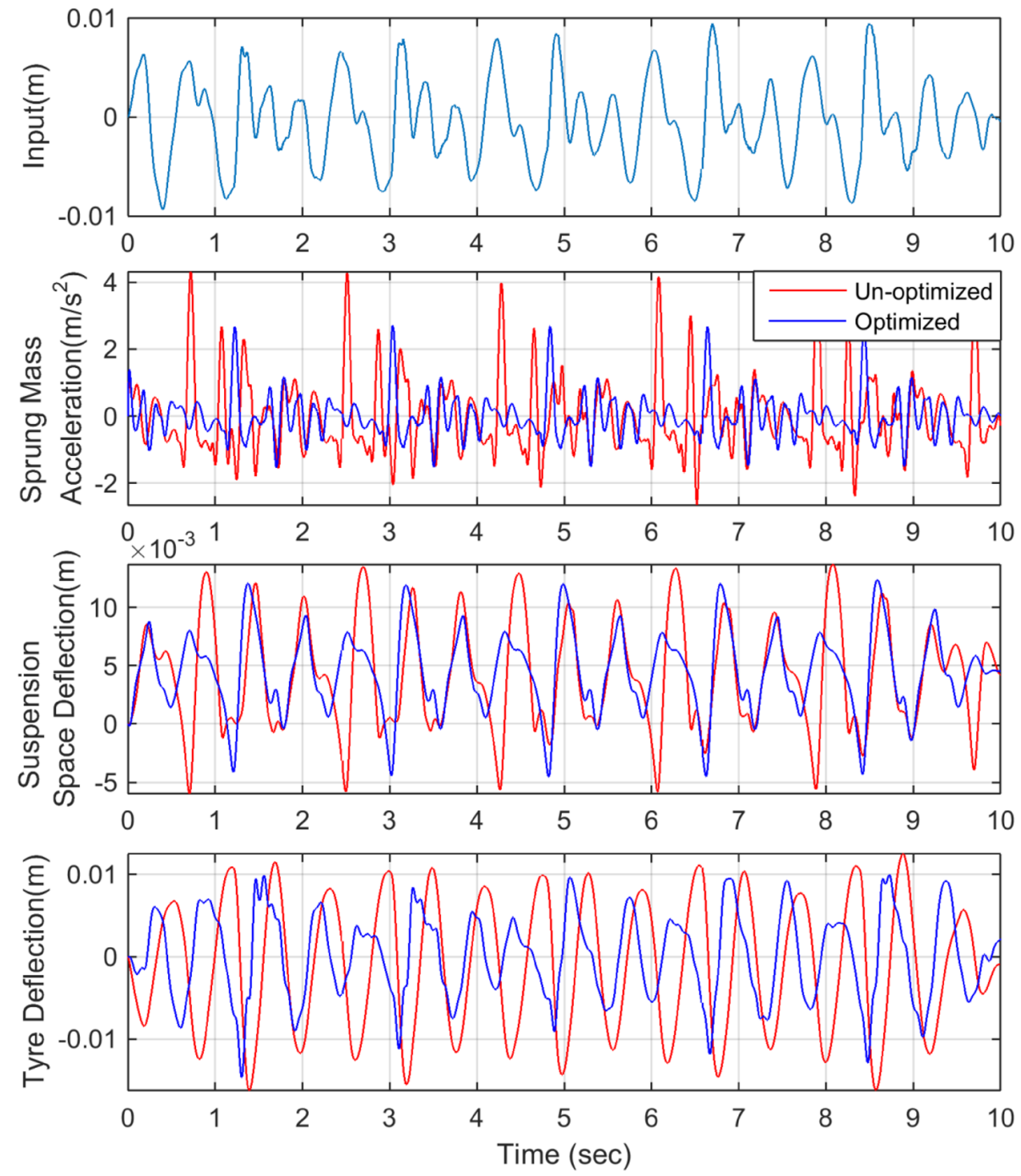

Table 6 Test rig results—un-optimized and optimized

\begin{tabular}{lll}
\hline Parameter & Un-Optimized & Optimized \\
\hline VDV & 2.8648 & 1.5673 \\
Aw & 1.0757 & 0.5695 \\
MTTV & 3.9336 & 2.2782 \\
RMS suspension space & 0.0062 & 0.0057 \\
RMS tyre deflection & 0.0081 & 0.0052 \\
Max acceleration & 4.3163 & 2.6997 \\
Max suspension space & 0.0137 & 0.0124 \\
Max tyre deflection & 0.0163 & 0.0146 \\
\hline
\end{tabular}

network based on input-output data sets. Generally in ANN data is divided into sets where one set is used to create the network one set is to train and one set is implement to validate the network. Once ANN is trained and validated then it is simulated for prediction purpose. As ANNs has prediction capabilities, it enhances the design process $[11,12,16-21]$.

\subsection{Artificial neural network fitting tool (nftool)}

Nftool is used for static fitting problems with standard two layer feed forward neural network trained with 
Fig. 15 Frequency response plot for simulated and experimental results-optimized strut

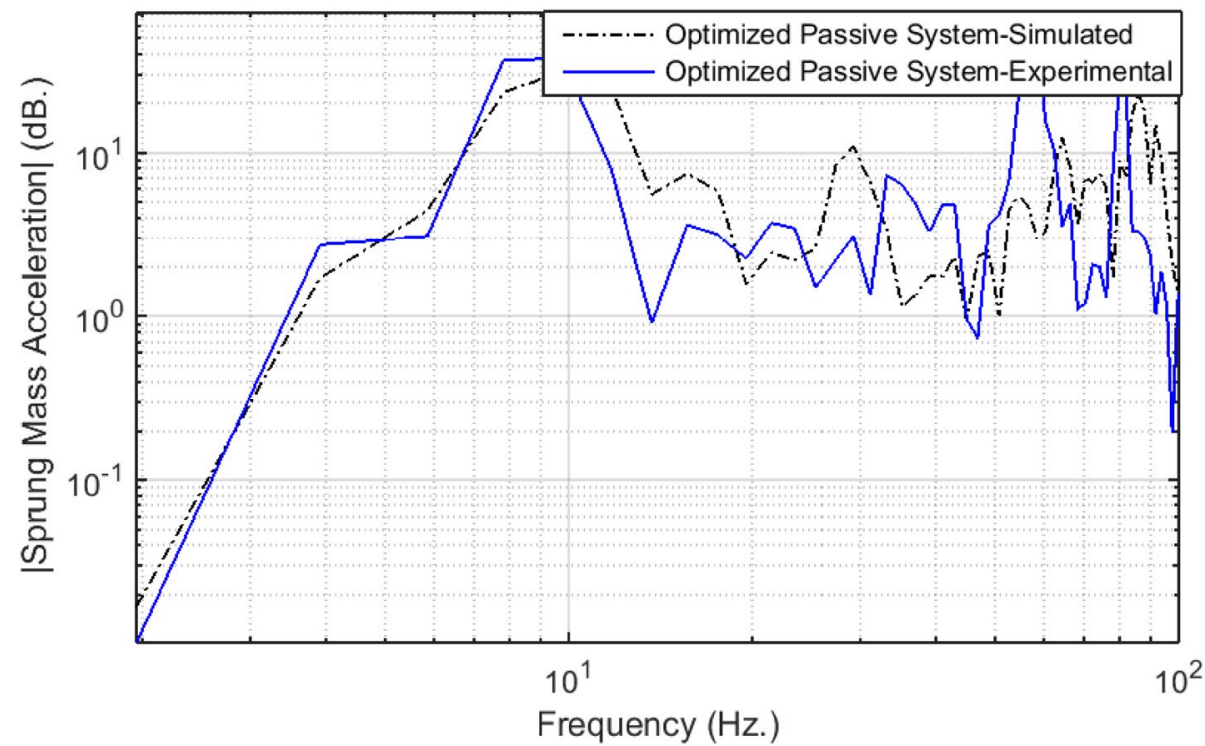

Levenberg-Marquardt (LM) algorithm. The training data set is the data obtained from last four generations out of 100 generations, i.e. 400 samples, of the optimization algorithm. The data supplied to the ANN is randomly subdivided as $70 \%$ for training, $15 \%$ for testing and $15 \%$ for validation. The training is automatic and the data is trained with scaled conjugate gradient. The performance of the network is evaluated by MSE and regression analysis. The training data is used to adjust network weights as per the error. To stop network training and to generalize the network validation data set is used. The network training is stopped when generalization stops improving. The testing data set provides a tool to analyze the performance of the network, during and after training. Thus test data has no effect on training. The training stops automatically when generalization stops improving as indicated by an increase in the mean square error of the validation data samples. Training multiple times generates different results due to different initialization of connection weights and different initial condition. The hidden layer neurons are increased when network is not performing well after training. The mean squared error is the average squared difference between normalized outputs and targets; zero means no error and over 0.6667 means higher error.

The ANN has five inputs-VDV, RMS acceleration, MTVV, RMS suspension space and RMS tyre deflection whereas two outputs-spring stiffness and damping.
ANN modeling by Matlab/Simulink environment consists of parameters shown in Table 2.

Figure 7 shows ANN topology utilized for modeling and simulation of the network using the parameters shown in Table 2. Figure 8 shows MSE variation concerning epoch for training, validation, and testing. Performance after training is having MSE $1.30 \times 10^{-6}$ at 44 epoch and best validation performance is $0.0,030,748$ at 38 epochs.

The validation error is minimum at 38th epoch, hence training was stopped at that point and weights and biases were used for further modeling. Correlation coefficients between targets (simulation values) and output (i.e. ANN output values) are shown Fig. 9. For training validation and testing. R-value is about 0.99999 for training, 0.99997 for validation and 0.99998 for testing.

\subsection{Neuro dimension (ND)}

Using same input and output datasets, ANN is also formed using Neuro Dimension (ND) software package, to check the accuracy of nftool, using parameters shown in Table 3. Nero Dimension ANN has average MSE is 0.004306 after 1000 epoch. Figure 10 shows the NN, output versus desired plot and learning curve.

Table 5 represents the suspension parameters obtained after optimization and prediction. 
Fig. 16 Time domain resultssimulation, experimental and ANN by matlab and ND
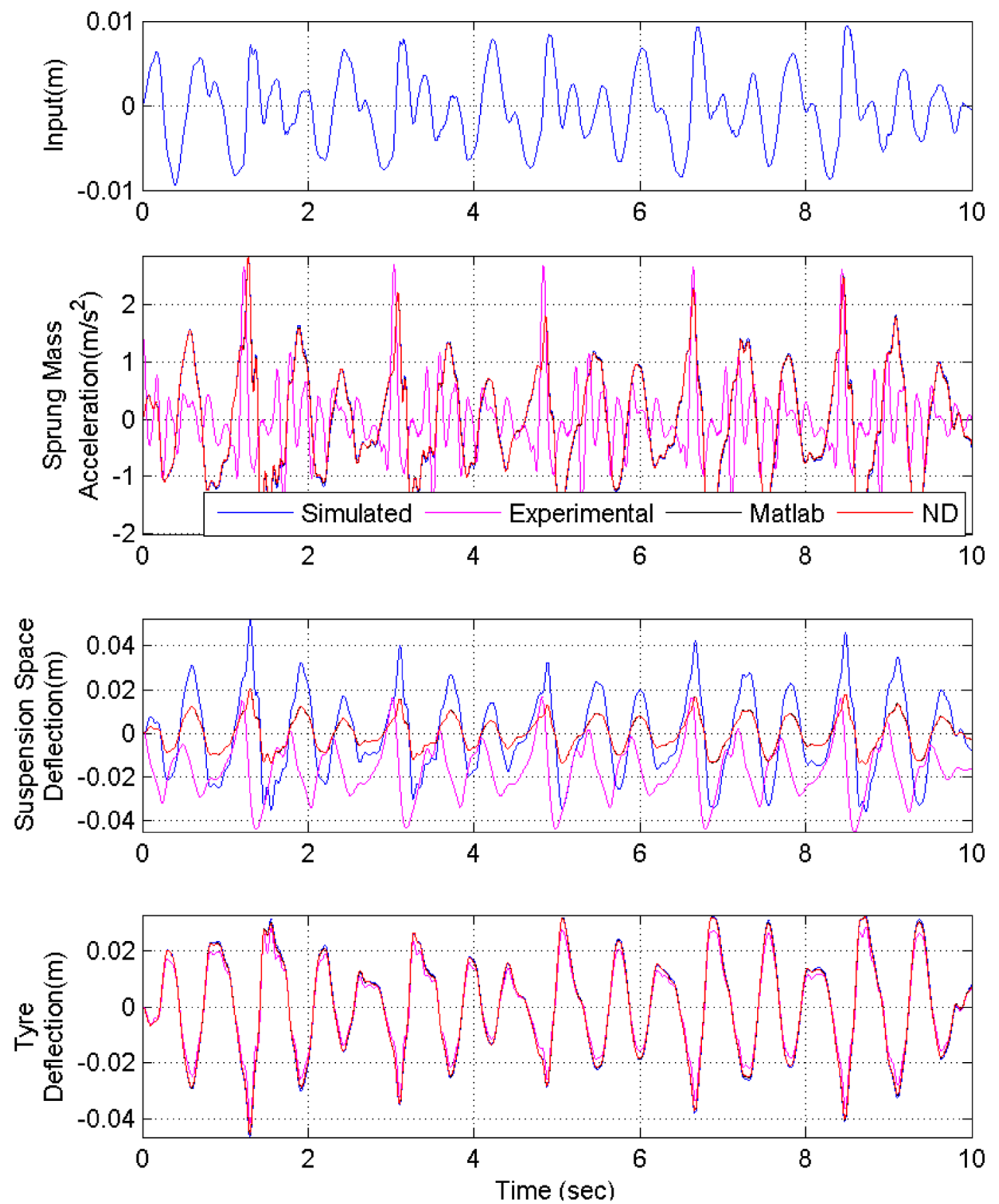

Table 7 Time domain results—un-optimized, optimized and ANN prediction

\begin{tabular}{|c|c|c|c|c|c|c|}
\hline \multirow[t]{2}{*}{ Parameter } & \multicolumn{2}{|c|}{ Un-optimized } & \multicolumn{2}{|l|}{ Optimized } & \multicolumn{2}{|l|}{ Predicted } \\
\hline & Simulation & Experimental & Simulation & Experimental & ANN-matlab & ANN-ND \\
\hline VDV & 2.5543 & 2.8648 & 1.332288 & 1.5673 & 1.3331 & 1.334183 \\
\hline Aw & 1.1707 & 1.0757 & 0.54721 & 0.5695 & 0.542125 & 0.540511 \\
\hline MTVV & 2.1649 & 3.9336 & 2.047462 & 2.2782 & 2.056311 & 2.060154 \\
\hline RMS suspension Space & 0.0071 & 0.0062 & 0.0075 & 0.0057 & 0.007338 & 0.007281 \\
\hline RMS tyre Deflection & 0.0068 & 0.008 & 0.0177 & 0.0052 & 0.017366 & 0.017228 \\
\hline Max acceleration & 4.9087 & 4.3136 & 2.8603 & 2.6997 & 2.84694 & 2.842026 \\
\hline Max suspension space & 0.0139 & 0.0137 & 0.020881 & 0.0124 & 0.020508 & 0.020362 \\
\hline Max tyre deflection & 0.0152 & 0.0163 & 0.046449 & 0.0146 & 0.045585 & 0.045247 \\
\hline
\end{tabular}


Table 8 Correlation of ANN results with simulated and experimental results

\begin{tabular}{llllll}
\hline Parameter & \multicolumn{2}{l}{$\%$ Correlation } & & & \\
\cline { 2 - 3 } & \multicolumn{2}{l}{ Simulated } & & & \multicolumn{2}{l}{ Experimental } & \\
\cline { 2 - 3 } \cline { 5 - 6 } & nftool-matlab & ANN-ND & & nftoolMatlab & ANN-ND \\
\hline VDV & 99.9390 & 99.8577 & 85.0571 & 85.1262 \\
Aw & 99.0707 & 98.7758 & & 95.1931 & 94.9098 \\
MTVV & 99.5678 & 99.3801 & & 90.2603 & 90.4290 \\
\hline
\end{tabular}

\section{Results and discussion}

Initially, the un-optimized strut is installed on the test rig and is excited by periodic motion at $4 \mathrm{~Hz}$ frequency and maximum amplitude $0.01 \mathrm{~m}$ as shown in Fig. 11. The data is acquired using FFT analyzer and processed further. Table 4 represents simulated and experimental results. VDV, RMS acceleration, MTTV, RMS suspension space and RMS tyre deflection obtained in experimental result are in close agreement with that of the simulated results. Figure 12 shows frequency response plot for simulated and experimental results for un-optimized strut.

The mathematical model is then simulated in Matlab/ Simulink environment using NSGA-II algorithm to obtain optimum suspension parameters. Trade-off front of 100 different solutions satisfying the constraints is obtained after optimization and is shown in Fig. 13. For ride comfort and health, the minimum value of RMS acceleration and VDV are the selection criterion for optimum suspension parameter values. Thus from trade-off front, values of spring stiffness $\mathrm{k}_{\mathrm{s}}$ and damping $\mathrm{c}_{\mathrm{s}}$ corresponding to minimum values of RMS acceleration and VDV are selected and simulated further. Refer Table 5 for corresponding optimized parameters.

The test rig with optimized parameters is then simulated and time domain results are shown in Fig. 14. The optimized suspension system is having lower values of sprung mass accelerations as compared to the un-optimized one. Thus the optimized system is having minimum values of VDV and RMS sprung mass acceleration. VDV is reduced by $45 \%$ in case of the optimized system. Also, RMS acceleration is reduced by $47 \%$, and MTVV is reduced by $42 \%$. Thus the optimized system improved ride comfort by reducing RMS acceleration and also improved health criterion by reducing the VDV. The optimized suspension system also follows constraints. Refer Table 6. Figure 15 shows frequency response plot for simulated and experimental results for optimized strut.

Here, Fig. 16 shows time response of simulated model, experimental results and ANN model by nftool in Matlab and ND. From Fig. 16 and Table 7, it is observed that VDV, $A w$, and MTVV for optimized suspension system are less as compared to un-optimized one thus improving ride comfort and health criterions. ANN approach validates same. Table 8 shows \% correlation of optimized results with the
Fig. 17 Comparative analysisun-optimized and optimized and predicted results

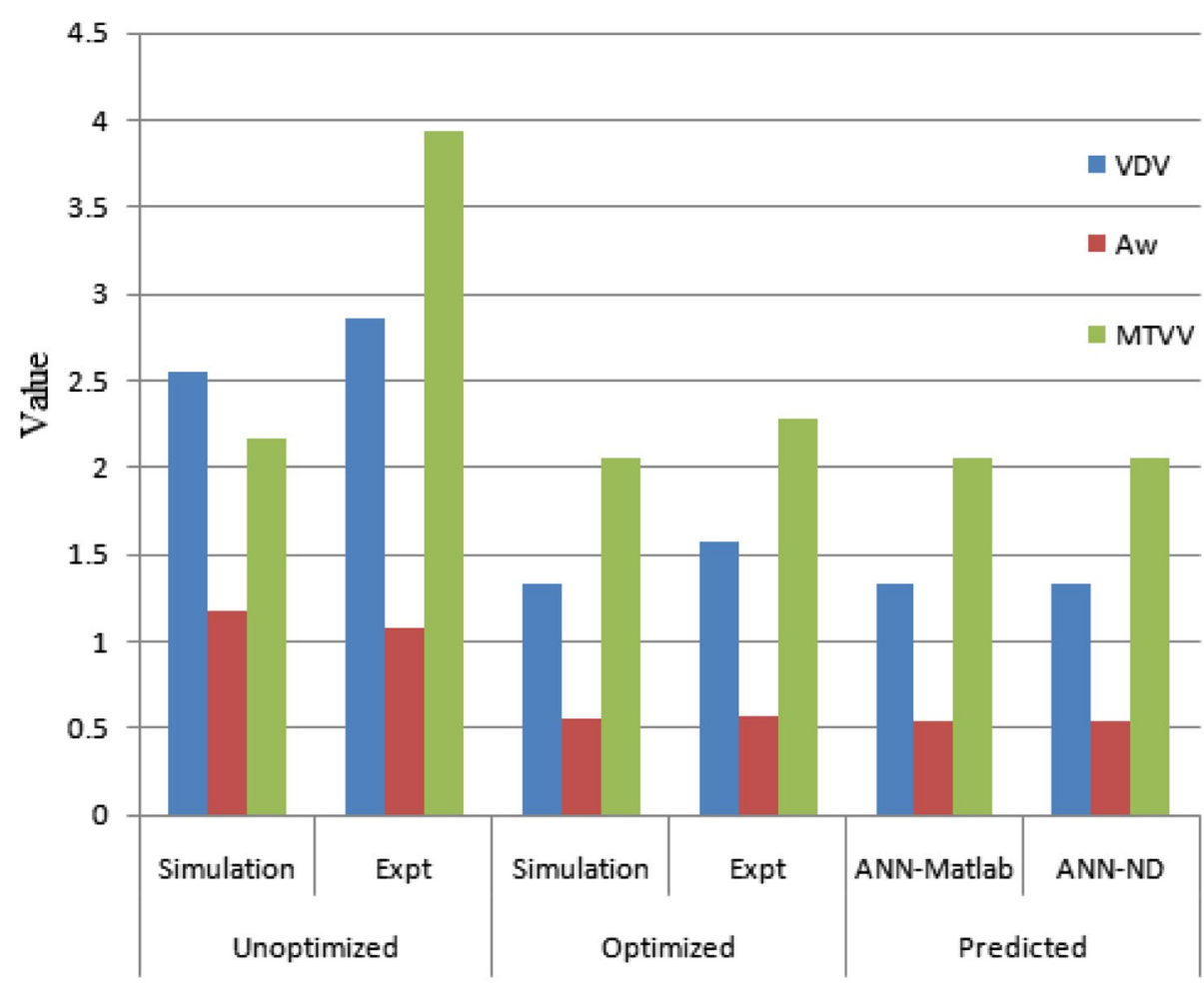

SN Applied Sciences A SPRINGER NATURE journa 
ANN approach. From Table 8 shows that the ANN results by both approaches, i.e., nftool in Matlab and ND are in close agreement having $98.77 \%$ correlation with simulated results. Whereas in case of experimental and predicted results by ANN, it is observed that VDV has $85 \%$ correlation, AW has $95 \%$ correlation, and MTVV has $90 \%$ correlation. Thus ANN results are also in good correlation with the experimental results. Hence using ANN one can predict the optimized suspension parameters with accuracy. Refer Fig. 17 for comparative bar chart.

\section{Conclusions}

- Quarter car with Macpherson strut suspension system mathematical model is developed and validated experimentally using test rig.

- Optimum design problem consists of comfort and health criterion according to ISO 2631-1 is adopted to assess the objective functions such as RMS acceleration, VDV, and MTVV to optimize the suspension parameters.

- The results show that the optimum suspension parameters using NSGA-II algorithm is implemented successfully for multi-objective optimization. Minimum values of VDV, RMS acceleration, MTVV along with stability criterions thus improving ride comfort and health criterions over classical or un-optimized design can be obtained. VDV is reduced by $45 \%$, RMS acceleration is reduced by $47 \%$, and MTVV is reduced by $42 \%$. By using the optimum suspension parameters

- A close correlation is observed between experimental and simulated results.

- Further, ANN is implemented to predict the optimum suspension parameters using nftool in Matlab and ND. ANN results shows $98-99 \%$ correlation with the simulated results whereas $85-95 \%$ correlation with experimental results.

- Thus, using ANN one can predict the suspension parameters with high accuracy.

Acknowledgements The first author likes to express his deep gratitude towards the management of Ahmednagar Jilha Maratha Vidya Prasarak Samaj, Ahmednagar for their encouragement and constant support to carry out this research work.

\section{Compliance with ethical standards}

Conflict of interest The authors declare that they have no conflict of interest.

\section{References}

1. Wong JY (2001) Theory of ground vehicles. Wiley, New York

2. Verros G, Natsiavas S, Papadimitriou C (2005) Design optimization of quarter-car models with passive and semi-active suspensions under random road excitation. JVC J Vib Control 11:581-606. https://doi.org/10.1177/1077546305052315

3. Baumal AE, McPhee JJ, Calamai PH (1998) Application of genetic algorithms to the design optimization of an active vehicle suspension system. Comput Methods Appl Mech Eng 163:87-94. https://doi.org/10.1016/S0045-7825(98)00004-8

4. Özcan D, Sönmez Ü, Güvenç L (2013) Optimisation of the nonlinear suspension characteristics of a light commercial vehicle. Int J Veh Technol 2013:1-16. https://doi.org/10.1155/2013/562424

5. Gobbi M, Mastinu G (2001) Analytical description and optimization of the dynamic behaviour of passively suspended road vehicles. J Sound Vib 245:457-481. https://doi.org/10.1006/ jsvi.2001.3591

6. Molina-Cristobal A, Papageorgiou C, Parks GT, Smith MC, Clarkson PJ (2006) Multi-objective controller design: evolutionary algorithms and bilinear matrix inequalities for a passive suspension. In: 13th IFAC workshop on control applications of optimization, pp 386-391

7. Geweda AE, El-Gohary MA, El-Nabawy AM, Awad T (2017) Improvement of vehicle ride comfort using genetic algorithm optimization and PI controller. Alex Eng J 56:405-414

8. Gohari M, Roslan AR, Raja IR, Tahmasebi M (2012) Bus seat suspension modification for pregnant women. In: International conference on biomedical engineering (ICOBE), Malaysia, pp 404-407

9. Frost G (1998) Stochastic optimisation of vehicle suspension control systems via learning automata. A Doctoral Thesis, Loughborough University

10. Gohari M, Tahmasebi M (2015) Active off-road seat suspension system using intelligent active force control. J Low Freq Noise Vib A 34(4):457-490. https://doi.org/10.1260/0263-0923.34.4.475

11. Gohari M, Tahmasebi M (2011) Determining and Optimization of vehicle seat suspension via artificial neural network modeling of Kitazaki spinal column model. In: First Iranian students scientific congress in Malaysia, 2011, pp 1-12

12. Gohari M, Roslan AR, Tahmasebi M (2011) Determining and optimization of vehicle seat suspension via artificial neural network modeling of coupled human-seat model. In: United KingdomMalaysia-Ireland engineering science conference 2011 (UMIES). University of Malaya, Malaysia

13. Zhao J, KinWong P, Ma X, Xie Z (2018) Design and analysis of an Integrated SMC-TPWP Strategy for a semi-active air suspension with stepper motor-driven GFASA. Proc Inst Mech Eng I J Syst 232:1194-1211. https://doi.org/10.1177/0959651818778217

14. Zhao F, Ge SS, Tu F, Qin Y, Dong M (2016) Adaptive neural network control for active suspension system with actuator saturation. IET Control Theory A 10(14):1696-1705. https://doi. org/10.1049/iet-cta.2015.1317

15. Qin Y, Zhao F, Wang Z, Gu L, Dong M (2017) Comprehensive analysis for influence of controllable damper time delay on semiactive suspension control strategies. J Vib Acoust 139(3):1-12

16. Dhingra AK, Rao SS (1992) A neural network based approach to mechanical design optimization. Eng Optim 20:187-203. https ://doi.org/10.1080/03052159208941280

17. Kalaivani R, Sudhagar K, Lakshmi $P$ (2016) Neural network based vibration control for vehicle active suspension system. Ind J Sci Technol 9(1):1-8

18. El-Gohary MA, El-Souhily BM, Rezeka SF, Awad T (2011) Generalized neural inverse dynamics model for front-wheel mid-size passenger car. Int Rev Mech Eng 5:474-482 
19. Marconcini M, Checcucci M, Sazzini F et al (2011) Assessment of a neural-network-based optimization tool: a low specific-speed impeller application. Int J Rotat. https://doi. org/10.1155/2011/817547

20. Sahu SN (2012) Neural network modelling and multi-objective optimization of EDM process, MTech Thesis. NIT Rourkela

21. Khalil MF, El-gohary MA, Shaito AA (2013) Application of artificial neural network for the prediction of trimmed impeller size of a centrifugal pump. In: Eleventh international conference of fluid dynamics, Alexandria, Egypt. ICFD11, pp 1-6

22. Gündoğdu Ö (2007) Optimal seat and suspension design for a quarter car with driver model using genetic algorithms. Int J Ind Ergon 37:327-332. https://doi.org/10.1016/j.ergon.2006.11.005

23. Hong KS, Jeon DS, Yoo WS, Sunwoo H, Shin SY, Kim CM, Park BS (1999), A new model and an optimal pole-placement control of the macpherson suspension system, SAE technical paper 199901-1331, pp 1-10

24. Gohari M, Tahmasebi M (2014) Off-road vehicle seat suspension optimisation, part II: comparative study between meta-heuristic optimisation algorithms. J Low Freq Noise V A 33(4):443-454

25. Holland JH (1992) Genetic algorithms. Sci Am 267:66-72. https ://doi.org/10.1038/scientificamerican0792-66

26. Song L (2011) NGPM-A NSGA-II program in matlab-user manual, version 2011, vol 4, no 1, pp 1-20

27. Song $L$ (2015) NGPM-A NSGA-II program in matlab v14. matlab code. http://in.mathworks.com/matlabcentral/fileexchan ge/31166-ngpm-a-nsga-ii-program-in-matlab-v1-4. Accessed 15 Mar 2015

28. Deb K, Pratap A, Agarwal S, Meyarivan T (2002) A fast and elitist multiobjective genetic algorithm: NSGA-II. IEEE Trans Evol Comput 6:182-197. https://doi.org/10.1109/4235.996017
29. Van Niekerk JL, Pielemeier WJ, Greenberg JA (2003) The use of seat effective amplitude transmissibility (SEAT) values to predict dynamic seat comfort. J Sound Vib 260:867-888. https:// doi.org/10.1016/S0022-460X(02)00934-3

30. Nagarkar MP, Vikhe Patil GJ, Zaware Patil RN (2016) Optimization of nonlinear quarter car suspension-seat-driver model. J Adv Res 7:991-1007. https://doi.org/10.1016/j.jare.2016.04.003

31. ISO: 2631-1 (1997) Mechanical vibration and shock-evaluation of human exposure to whole-body vibration. ISO, Geneva

32. Alander JT (1992) On optimal population size of genetic algorithms. In: Alander. CompEuro'92. Computer systems and software engineering, pp 65-70. https://doi.org/10.1109/CMPEU R.1992.218485

33. Rosenthal S, Borschbach M (2014) Impact of population size and selection within a customized NSGA-II for biochemical optimization assessed on the basis of the average cuboid volume indicator. In: Proceedings of sixth international conference on bioinformatics, biocomputational systems and biotechnologies, BIOTECHNO 2014, pp 1-7

34. Hernández-Díaz AG, Coello CAC, Pérez F et al (2008) Seeding the initial population of a multi-objective evolutionary algorithm using gradient-based information. In: 2008 IEEE congress on evolutionary computation, CEC 2008, pp 1617-1624. https:// doi.org/10.1109/CEC.2008.4631008

Publisher's Note Springer Nature remains neutral with regard to jurisdictional claims in published maps and institutional affiliations. 